\title{
3 Research Square \\ Medical Malpractice and Trigeminal Neuralgia: An Analysis of 49 Cases
}

\author{
Andre E. Boyke \\ Montefiore Medical Centre \\ Ishan Naidu \\ Montefiore Medical Center https://orcid.org/0000-0002-3859-4719 \\ Sharon Lam \\ Montefiore Medical Center \\ Mohammed Ali Alvi \\ Mayo Clinic Minnesota \\ Edward R. Bader \\ Yeshiva University Albert Einstein College of Medicine \\ Atharv Sethi \\ Montefiore Medical Center \\ Vijay Agarwal ( $\sim$ vagarwal@montefiore.org)
}

\section{Research article}

Keywords: Trigeminal Neuralgia, Medicolegal, Medical Malpractice, Neurosurgery

Posted Date: August 3rd, 2020

DOI: https://doi.org/10.21203/rs.3.rs-51207/v1

License: (c) (i) This work is licensed under a Creative Commons Attribution 4.0 International License. Read Full License

Version of Record: A version of this preprint was published on December 29th, 2020. See the published version at https://doi.org/10.1016/j.joms.2020.12.041. 


\section{Abstract}

\section{Background}

Our study aims to fill the vacancy of litigation studies related to trigeminal neuralgia management, and to give healthcare providers the necessary information needed to better understand the potential litigious outcomes that often follow certain treatment methods.

\section{Methods}

We queried the Westlaw Edge legal database to identify litigation cases related to the management of trigeminal neuralgia for the years 1985-2019 using the following search criteria: (trigeminal \& neuralgia), (tic \& douloureux) and (microvascular \& decompression). Key variables extracted included the following: plaintiff medical complaints, trial outcome, payout, and demographic characteristics. Continuous variables were compared between cases in favor of defendant and cases in favor of plaintiff using t-test or Wilcoxon rank sum test. Categorical variables were compared using chi-square or Fischer's exact test.

\section{Results}

49 cases met the inclusion criteria - for those cases surgical complication $(42.9 \%)$ and failure to diagnose (32.7\%) were cited as the most common alleged reasons for filing a malpractice claim. Cranial nerve deficits (34.7\%) and loss of consortium (12.2\%) were the most frequent post-operative complaints. Verdicts ruled in favor of the defendant in $61.2 \%$ of cases, and for the plaintiff in $26.5 \%$ of cases with a mean payout of $\$ 1,982,428.46$. Dental specialists were included in the most cases, $63.3 \%$, and the average payout was $\$ 415,908$, while Neurosurgical specialists were involved in $20.4 \%$ of cases with an average payout of $\$ 618,775$. Cases where the verdict was in favor of the plaintiff were more likely to be older than cases with a verdict in favor of the defendant $(p=0.03)$.

\section{Conclusions}

Over one-half of the cases resulted in a defendant's verdict with surgical complications cited as the most common reason for litigation. Dentistry and neurosurgery were listed as the most common individual physician specialties for defendants, also contributing to the largest average payouts based on specialty (for specialties $>1$ occurrence). Cranial nerve deficits and loss of consortium were the most common plaintiff post-operative complaints. A key implication of this study is the need for more extensive discussions between physician and patient regarding informed consent, especially when neurosurgical interventions are required.

\section{Background}

Patient litigation remains an ongoing concern for many licensed medical practitioners. Medical malpractice lawsuits have been a common occurrence in the United States since 1960.[1] Due to the consequential nature of neurosurgical procedures, physicians within the specialty face a high risk of 
malpractice lawsuits. The malpractice risk for general surgeons and neurosurgeons is especially high, being around $65 \%$ and $95 \%$ respectively.[2] Although there are relatively high occurrences of litigation within surgery, research detailing the weight of these effects for different specialties and diagnoses remains relatively scarce. Of these, procedures involving head and neck surgeries have been studied for medical litigation. To our knowledge, examination of malpractice due to the surgical treatment of trigeminal neuralgia has not yet been conducted.

Trigeminal neuralgia (TN) is a chronic pain condition presenting in the trigeminal nerve distribution which often occurs when the nerve is compressed by a blood vessel or tumor. The typical presentation may include recurrent paroxysms of unilateral, severe shooting, and burning pain which can be triggered by gentle touching of the face, chewing, or while brushing teeth.[4] Causes for these presentations may be due to aging, effects of stroke-like symptoms, or damage to the myelin nerve sheath. Dental ailments and surgical procedures can also mimic TN. In order to treat the commonly chronic, and very severe, pain that can occur from TN, a series of medical treatments are usually initially applied. Primarily these treatments include sodium channel blockers (e.g. carbamazepine and oxcarbazepine).[5] If combination medical treatments are unhelpful, procedures such as microvascular decompression or stereotactic radiosurgery may be employed. Other surgical treatment methods can be undertaken depending on the cause of the TN.

There have been case reports of patients with atypical presentations of trigeminal neuralgia in whom a diagnosis was missed. [4] There have also been presented cases of patients in whom a trigeminal neuropathy was uncovered after a dental procedure.[6] Such cases have also been reported in the media after patients decided to file a lawsuit. [7, 8] However, to our knowledge to date, no study has comprehensively examined lawsuits filed by patients with respect to the surgical management of trigeminal neuralgia. Our study aims to fill the vacancy of litigation studies related to TN management, and to give physicians and other healthcare providers the necessary information needed to better understand the potential litigious outcomes that often follow certain treatment methods.

\section{Methods}

\section{Data Source}

For the current study, we queried the Westlaw Edge (Thomson Reuters) online legal database with the aim of identifying public litigation cases related to the management of trigeminal neuralgia for the years 1985-2019.[9] The database Westlaw Edge serves as a comprehensive national repository for legal cases from all court levels across the United States of America. Cases presented in Westlaw are screened for accuracy by attorneys. $[10,11]$

Cohort

Cases documented as Jury Verdicts and Settlements from all Federal and State level courts were searched. Legal cases were included in the study provided that they were related to one individual patient, 
and the allegation was directly related to engagement with medical staff who diagnosed or managed trigeminal neuralgia. In order to obtain the most comprehensive number of cases from the database, the following search criteria was used: (trigeminal \& neuralgia), (tic \& douloureux) and (microvascular \& decompression). The " $\&$ " function ensures that the retrieved results include all the search terms.

Outcomes and Covariates of Interest

Trigeminal neuralgia data was extracted from the Westlaw database. The variables extracted included the following: plaintiff and defendant background, trial year, litigation category, plaintiff medical complaints, trial outcome, and payout if applicable. Demographic characteristics of patient age and sex were also recorded. These characteristics were then compared based on verdict in favor of the defendant (physician) and cases with a verdict in favor of the plaintiff.

Statistical Analysis

Continuous variables were summarized using means and standard deviations and compared between cases in favor of defendant and cases in favor of plaintiff using t-test or Wilcoxon rank sum test. Categorical variables were summarized using frequencies and proportions and compared between the two groups using chi-square or Fischer's exact test.

\section{Results}

\section{Table 1 here}

132 cases relating to trigeminal neuralgia and medical malpractice occurring from 1985 to 2019 were obtained from the primary search. Of those, 83 cases were excluded from the study due to litigation focused on a motor vehicle accident, insufficient information about the case, or the presence of duplicate cases. After screening, there were a total of 49 cases eligible for inclusion in this analysis.

\section{Demographics}

Of the total 49 cases, $13(26.5 \%)$ were male, 35 (71.4\%) were female, and 1 (2.0\%) was of unknown sex (Table 1). The average age of those who filed a claim was 48.1 years (range 22 to 78 years old).

Geographic Distribution

Cases involving trigeminal neuralgia were declared across 17 states in the United States. Notably, New York $(n=11 ; 22.4 \%)$ had the greatest number of cases, with California and Pennsylvania following with 7 (14.3\%) cases each (Table 1).

Reasons for Litigation

Occurrence of a surgical complication $(n=21 ; 42.9 \%)$ was cited as the most common alleged reason for filing a malpractice claim. The second most common reason was failure to diagnose $(n=16 ; 32.7 \%)$. 
Other cases cited failure of informed consent $(n=6 ; 12.2 \%)$, failure to treat $(n=5 ; 10.2 \%)$, and imaging complications $(n=1,2.0 \%)$ (Table 1$)$.

Plaintiff Complaints or Outcomes involved in Claim

For pre-operative symptoms, including symptoms reported by patients who never underwent a procedure, cranial nerve deficits $(n=10 ; 20.4 \%)$ and financial loss $(n=2 ; 4.1 \%)$ were the most frequent complaints (Table 1 and Figure 1). Other complaints included loss of consortium, facial paralysis, speech impairment, quadriplegia, and headache or chronic headache each represented in 1 (2\%) case.

Post-operative grievances included cranial nerve deficits $(n=17 ; 34.7 \%)$, loss of consortium $(n=6 ; 12.2 \%)$, financial loss $(n=4 ; 8.2 \%)$, death $(n=4 ; 8.2 \%)$, and emotional distress $(n=3 ; 6.1 \%)$ (see Table 1 and Figure 1). New post-operative symptoms afflicting patients in the presented cases most commonly included vision impairment or loss $(n=3 ; 6.1 \%)$, facial paralysis $(n=3 ; 6.1 \%)$, and deafness and motor weakness both with $2(4.1 \%)$ cases each. Less common symptoms included hemorrhage, ischemic stroke, disequilibrium, and memory loss each with 1 (2.0\%) case.

Plaintiff pre-operative and post-operative complaints for trigeminal-neuralgia related cases from 1985 to 2019

\section{Figure 1 here}

Figure 1: The most frequent pre-operative plaintiff complaints were cranial nerve injury $(n=10 ; 20.4 \%)$ and financial loss $(n=2 ; 4.1 \%)$. The most frequent post-operative plaintiff complaints were cranial nerve injury $(n=17 ; 34.7 \%)$, loss of consortium $(n=6 ; 12.2 \%)$, and financial loss and death, both reported for $4(8.2 \%)$ cases. Additional post-operative symptoms included vision impairment or loss $(n=3 ; 6.1 \%)$ and facial paralysis $(n=3 ; 6.1 \%)$, followed by deafness $(n=2 ; 4.1 \%)$ and motor weakness $(n=2 ; 4.1 \%)$.

Specialties of Defendants

Of the 49 cases included, the most frequently implicated defendant specialties were Dentistry $(n=31$; $63.3 \%)$ and Neurosurgery $(n=10 ; 20.4 \%)$ (Table 1). A hospital, medical center, or healthcare system was involved in $9(18.4 \%)$ cases. Anesthesiology, Family Medicine, Internal Medicine, Otolaryngology, and Radiology each were involved in $1(2 \%)$ case.

Legal Jurisdiction, Verdict, and Payments

Information on case outcome was available for 46 of the cases included in this study. A verdict was reached at the state level for all of these cases. Verdicts ruled in favor of the defendant in $30(61.2 \%)$ of cases, and for the plaintiff in $13(26.5 \%)$. A settlement was reached in $3(6.1 \%)$ cases. The payout range for all verdicts ranged from $\$ 55,000-7,978,185$. The mean payout for verdicts in favor of the plaintiff was $\$ 1,982,428.46$, which was greater than the $\$ 660,724.67$ mean for settlements. When considering payouts based on specialty, the largest amount was in a single case involving Anesthesiology, where the 
payout was $\$ 7,978,185$ (Table 2). The next highest average payout was $\$ 1,030,898$ over 9 cases against a hospital, medical center, or healthcare system group. Dental specialists were included in the most cases, $31(63.3 \%)$, and the average payout was $\$ 415,908$. Neurosurgical specialists were involved in 10 $(20.4 \%)$ cases which were found to have an average payout of $\$ 618,775$.

Table 2: Average payout based on medical specialty of the defendant

\begin{tabular}{|ll|}
\hline Specialties of Defendants & Average Payout \\
\hline Anesthesiology & $\$ 7,978,185$ \\
\hline Dentistry & $\$ 415,908$ \\
\hline Family Practice & $\$-$ \\
\hline Hospital, Medical Center, or Healthcare System & $\$ 1,030,898$ \\
\hline Internal Medicine & $\$-$ \\
\hline Neurosurgery & $\$ 618,775$ \\
\hline Oral and Maxillofacial Surgery & $\$-$ \\
\hline Otolaryngology & $\$-$ \\
\hline Radiology & $\$-$ \\
\hline
\end{tabular}

We also compared characteristics between cases which had a verdict in favor of the defendant $(n=30)$ and those in favor of plaintiff $(n=13)$. Cases where the verdict was in favor of the plaintiff were more likely to be older ( $55.6 \pm 12.9$ vs $42.9 \pm 12.5, p=0.03$ ). Other factors found to be different but not approaching statistical significance included defendant's position where cases in favor of the plaintiff were more likely to involve physicians $(53.8 \%, n=7$ vs $30 \%, n=9, p=0.137)$; type of lawsuit where cases in favor of plaintiff were more likely to be malpractice lawsuits $(66.7 \%, n=8$ vs $36.7 \%, n=11, p=0.078)$. Finally, cases with verdict in favor of plaintiff, compared to those with verdict in favor of defendant, were more likely to involve a litigation of failure to treat and informed consent failure (failure to treat: $23.1 \%$, $n=3$ vs $6.7 \%, n=6$; informed consent failure: $23.1 \%, n=3$ vs $3.3 \%, n=1$; overall $p=0.093$ ).

\section{Table 3 here}

\section{Discussion}

This study presents a 34-year analysis of medical malpractice litigation in the United States of America pertaining to the management of trigeminal neuralgia. TN characteristically worsens over time, as the remission period becomes shorter and medications become less effective. Further, the intrusive nature of the condition can complicate simple daily activities, such as eating, talking, and maintaining oral hygiene. [12] Due to the characteristic symptoms of the condition, it is not surprising that litigation often followed procedures that incited or worsened the facial pain in afflicted patients. 
Our analysis identified New York $(n=11 ; 22.4 \%)$, California $(n=7 ; 14.3 \%)$, and Pennsylvania $(n=7 ; 14.3 \%)$ as the states with the highest number of trigeminal neuralgia-related litigation cases (Table 1). All three states are in the top five for population in the United States, thus it logically follows that a higher proportion of cases are represented in these states. Additionally, neither New York nor Pennsylvania has a cap on malpractice damages, while other states we identified with a lower number of trigeminal neuralgia cases, such as Colorado, Kansas, Maryland, Michigan, Ohio, and Washington, all have caps on malpractice damages awarded to plaintiffs, providing less of an incentive to pursue litigation.

In this study, the most common reasons for litigation were surgical complications ( $n=21 ; 42.9 \%)$ and failure to diagnose ( $n=16 ; 32.7 \%)$ (see Table 1 and Figure 1$)$. These findings are consistent with a previous study of medical malpractice in neurosurgery that found procedural error (45.5\%) and failure to diagnose (41.4\%) as the top cited reasons for litigation. [13] Cranial nerve deficits $(n=17 ; 34.7 \%)$ and loss of consortium ( $n=6 ; 12.2 \%$ ) were the most numerous post-operative complaints (Figure 1 ). Cranial nerve deficits can not only result in additional complaints of vision impairment or loss, facial paralysis, deafness, and other deficits, but they can also exacerbate symptoms of trigeminal neuralgia, providing a potential correlation between the high frequencies of surgical complication as a reason for litigation and cranial nerve deficits as a post-operative complaint.

Although trigeminal neuralgia is most commonly initially treated nonoperatively with an anticonvulsant medication such as carbamazepine, the etiology of the disease (e.g. MS, blood vessel or tumor compression, facial trauma) and severity of pain may necessitate surgical intervention. Microvascular decompression has been found to sustain pain relief in $73 \%$ of patients over 5 years. [5] As with many invasive surgical procedures, this treatment approach does not come without risks such as aseptic meningitis, sensory loss, and hearing loss.[5]

The two defendant specialties most commonly cited in claims were Dentistry $(n=31 ; 63.3 \%)$ and Neurosurgery $(n=10 ; 20.4 \%)$ (Table 1$)$. The vast majority of claims studied were filed against defendants involved in dentistry. This is likely because trigeminal neuralgia commonly presents with gum and tooth pain with chewing, and dentists are the specialists frequently consulted first, contributing to their large representation in legal claims.[15] This might also explain why a large majority of cases resulted in a favorable verdict for the defendant in these cases $(n=30 ; 61.2 \%)$ (Table 1$)$. The condition may have been pre-existing and simply manifested after a visit to the defendant, also potentially refuting plaintiff claims of surgical complications.

The highest average payout based on defendant specialty was for Anesthesiology at \$7,978,185. However, there was only a single case involving this specialty. Neurosurgery presented as the specialty with the highest average payout (for specialties with $N>1$ ) at $\$ 618,775$. Neurosurgeons are responsible for the surgical, and often stereotactic, treatment of trigeminal neuralgia, such as percutaneous procedures on the Gasserian ganglion, gamma knife surgery, and microvascular decompression, thus it logically follows that this specialty is one of the most commonly represented specialties in lawsuits and payouts pertaining to trigeminal neuralgia.[16] 
Our finding that cases with physicians as defendants were more likely to result in a verdict in favor of the plaintiff has previously been demonstrated by Shantharam et al., who investigated factors associated with outcomes of malpractice litigation among patients with spinal epidural abscess and found a similar association.[17] The same study found that a delay in treatment was associated with a verdict more likely in favor of the plaintiff. [17] Finally, our finding that informed consent failure was associated often with a verdict in favor of the defense warrants a specific discussion. A study by Cassileth et al. showed that among patients who were tested on their recall of the details of the informed consent 24 hours after it was obtained, only $60 \%$ remembered the purpose of the treatment and only half of the patients could list one potential complication. [18] This underscores the need for clear and explicit consent for the surgical or radiosurgical treatment of trigeminal neuralgia. Patients afflicted with this condition are often desperate for a solution due to the extreme pain. The potential risks of intervention need to be clearly expressed and all questions answered in full. It is wise to have family members involved with the discussion of the risks, and also a thorough discussion of all the treatment options that are available, including continued non-procedural or medical management.

One limitation in our analysis is that only 47 cases met the inclusion criteria. Though multiple search terms, such as "Trigeminal Neuralgia", "Tic Douloureux", and "Microvascular Decompression" were used to filter cases, many cases were excluded as they included duplicates or non-medical related primary incidents. Additionally, the Westlaw database excludes cases mediated outside of the court system and only includes cases reported at the discretion of state courts.

Another limitation to the database is that the trial data documented in Westlaw is recorded by nonmedical professionals, which leads to less medically relevant information regarding the interventional procedures performed by the defendants. Such information could potentially provide context to the postoperative complaints and trial outcomes if include

\section{Conclusions}

Our study presents a 34-year analysis of trigeminal neuralgia-related medical malpractice suits in the United States. Over one-half of the cases resulted in a defendant's verdict with surgical complications cited as the most common reason for litigation. Dentistry and neurosurgery were listed as the most common individual physician specialties for defendants, also contributing to the largest average payouts based on specialty (for specialties $>1$ occurrence). Cranial nerve deficits, loss of consortium, financial loss, and death were the most common plaintiff complaints.

\section{Declarations}

\section{Ethics Approval and consent to participate}

Not applicable

\section{Consent for publication}


Not applicable

\section{Availability of data and materials}

The data that support the findings of this study are available from Westlaw Edge database, but restrictions apply to the availability of these data, which were used under license for the current study, and so are not publicly available. Data are however available from the authors under reasonable request and with permission of Thomson Reuters.

\section{Competing interests}

The authors declare that they have no competing interests.

\section{Funding}

Not applicable

\section{Authors' contributions}

$A B$ conceived of the project and presented ideas under the guidance of VA and MA. AB developed and refined the relevant variables for analysis. IN and SL collected and organized the relevant data from the database, and IN and MA performed the calculations and designed the tables and figures. IN, SL, and MA conducted statistical analyses on the data. $A B$ took the lead on writing the manuscript with input from IN, $M A, A S, E B$, and VA. AB, IN, and MA contributed to the interpretation of the results. All authors discussed contributed to the final manuscript.

\section{Acknowledgements}

Not applicable

\section{References}

1. Kessler DP (2011) Evaluating the medical malpractice system and options for reform. J Econ Perspect 25:93-110

2. Stahel PF (2017) Surgical Patient Safety: A Case-Based Approach. McGraw Hill Professional

3. Jena AB, Seabury S, Lakdawalla D, Chandra A (2011) Malpractice risk according to physician specialty. N Engl J Med 365:629-636

4. Duvall JR, Robertson CE (2019) Clinical Reasoning: A misdiagnosis of atypical trigeminal neuralgia. Neurology 93:124-131

5. Obermann M (2019) Recent advances in understanding/managing trigeminal neuralgia. F1000Res 8.: https://doi.org/10.12688/f1000research.16092.1

6. Agbaje JO, Van de Casteele E, Hiel M, et al (2016) Neuropathy of Trigeminal Nerve Branches After Oral and Maxillofacial Treatment. J Maxillofac Oral Surg 15:321-327 
7. Camosy PA (1999) Medical mysteries. Arch. Fam. Med. 8:294-295

8. GGCRBHS\&M (2016) Failure to diagnose trigeminal neuralgia can be medical malpractice that can cause extreme pain to a patient. In: New York Personal Injury Attorneys

Blog.https://www.newyorkpersonalinjuryattorneysblog.com/failure-diagnose-trigeminal-neuralgiacan-medical-malpractice-can-cause-extreme-pain-patient/. Accessed 13 Jul 2020

9. Westlaw - Online Legal Research. Reuters

10. Choudhry AJ, Haddad NN, Martin M, et al (2017) Medical Malpractice in Bariatric Surgery: a Review of 140 Medicolegal Claims. J Gastrointest Surg 21:146-154

11. Grauberger J, Kerezoudis P, Choudhry AJ, et al (2017) Allegations of Failure to Obtain Informed Consent in Spinal Surgery Medical Malpractice Claims. JAMA Surg 152:e170544

12. Zakrzewska JM, Linskey ME (2014) Trigeminal neuralgia. BMJ Clin Evid 2014:

13. Trigeminal Neuralgia - Causes, Symptoms and Treatments. https://www.aans.org/Patients/Neurosurgical-Conditions-and-Treatments/Trigeminal-Neuralgia. Accessed 22 Jul 2020

14. von Eckardstein KL, Keil M, Rohde V (2015) Unnecessary dental procedures as a consequence of trigeminal neuralgia. Neurosurg Rev 38:355-60; discussion 360

15. Obermann M (2010) Treatment options in trigeminal neuralgia. Ther Adv Neurol Disord 3:107-115

16. Shantharam G, DePasse JM, Eltorai AEM, et al (2018) Physician and patients factors associated with outcome of spinal epidural abscess related malpractice litigation. Orthop Rev 10:7693

17. Cassileth BR, Zupkis RV, Sutton-Smith K, March V (1980) Informed Consent - Why Are Its Goals Imperfectly Realized? New England Journal of Medicine 302:896-900

\section{Tables}

Table 1: Summary of Key Characteristics 


\begin{tabular}{|c|c|}
\hline Variable & Total $n=49$ \\
\hline \multicolumn{2}{|l|}{ Demographics } \\
\hline Age (Mean \pm SD) & $48.1 \pm 14.8$ \\
\hline Females $(\mathrm{n},(\%))$ & $35(71.4 \%)$ \\
\hline \multicolumn{2}{|c|}{ Geographic Distribution (n (\%)) } \\
\hline Alabama & $1(2.0 \%)$ \\
\hline California & $7(14.3 \%)$ \\
\hline Colorado & $1(2.0 \%)$ \\
\hline Connecticut & $1(2.0 \%)$ \\
\hline Florida & $4(8.2 \%)$ \\
\hline Kansas & $1(2.0 \%)$ \\
\hline Kentucky & $1(2.0 \%)$ \\
\hline Maryland & $1(2.0 \%)$ \\
\hline Michigan & $2(4.1 \%)$ \\
\hline Minnesota & $1(2.0 \%)$ \\
\hline Missouri & $3(6.1 \%)$ \\
\hline New Jersey & $5(10.2 \%)$ \\
\hline New York & $11(22.4 \% \%)$ \\
\hline Ohio & $1(2.0 \%)$ \\
\hline Pennsylvania & $7(14.3 \%)$ \\
\hline Virginia & $1(2.0 \%)$ \\
\hline Washington & $1(2.0 \%)$ \\
\hline \multicolumn{2}{|l|}{ Type of Court } \\
\hline Circuit Court & $10(20.4 \%)$ \\
\hline Court of Common Pleas & $8(16.3 \%)$ \\
\hline District Court & $3(6.1 \%)$ \\
\hline Superior Court & $13(26.5 \%)$ \\
\hline
\end{tabular}




\begin{tabular}{|c|c|}
\hline Supreme Court & $8(16.3 \%)$ \\
\hline Unknown State Court & $7(14.3 \%)$ \\
\hline \multicolumn{2}{|l|}{ Malpractice vs Negligence Lawsuit } \\
\hline Malpractice & $24(49.0 \%)$ \\
\hline Negligence & $24(49.0 \%)$ \\
\hline N/A & $1(2.0 \%)$ \\
\hline \multicolumn{2}{|l|}{ Reasons for Litigation (n (\%))* } \\
\hline Surgical complications & $21(42.9 \%)$ \\
\hline Failure to diagnose & $16(32.7 \%)$ \\
\hline Failure of informed consent & $6(12.2 \%)$ \\
\hline Failure to treat & $5(10.2 \%)$ \\
\hline Imaging complications & $1(2.0 \%)$ \\
\hline \multicolumn{2}{|l|}{ Plaintiff Complaints (n, (\%)) } \\
\hline \multicolumn{2}{|c|}{ Preoperative Claims / Those who did not undergo Surgery } \\
\hline Cranial Nerve Deficits & $10(20.4 \%)$ \\
\hline Financial Loss & $2(4.1 \%)$ \\
\hline Facial Paralysis & $1(2.0 \%)$ \\
\hline Headache or Chronic Headache & $1(2.0 \%)$ \\
\hline Loss of Consortium & $1(2.0 \%)$ \\
\hline Quadriplegia & $1(2.0 \%)$ \\
\hline Speech Impairment & $1(2.0 \%)$ \\
\hline \multicolumn{2}{|l|}{ Post-operative Claims } \\
\hline Cranial Nerve Deficits & $17(34.7 \%)$ \\
\hline Loss of Consortium & $6(12.2 \%)$ \\
\hline Death & $4(8.2 \%)$ \\
\hline
\end{tabular}




\begin{tabular}{|c|c|}
\hline Financial Loss & $4(8.2 \%)$ \\
\hline Emotional Distress & $3(6.1 \%)$ \\
\hline Facial Paralysis & $3(6.1 \%)$ \\
\hline Vision Impairment or Loss & $3(6.1 \%)$ \\
\hline Deafness & $2(4.1 \%)$ \\
\hline Motor Weakness & $2(4.1 \%)$ \\
\hline Disequilibrium & $1(2.0 \%)$ \\
\hline Hemorrhage & $1(2.0 \%)$ \\
\hline Memory Loss & $1(2.0 \%)$ \\
\hline Stroke & $1(2.0 \%)$ \\
\hline \multicolumn{2}{|l|}{ Specialties of Defendants } \\
\hline Dentistry & $31(63.3 \%)$ \\
\hline Neurosurgery & $10(20.4 \%)$ \\
\hline Hospital, Medical Center, or Healthcare System & $9(18.4 \%)$ \\
\hline Oral and Maxillofacial Surgery & $2(4.1 \%)$ \\
\hline Anesthesiology & $1(2.0 \%)$ \\
\hline Family Practice & $1(2.0 \%)$ \\
\hline Internal Medicine & $1(2.0 \%)$ \\
\hline Otolaryngology & $1(2.0 \%)$ \\
\hline Radiology & $1(2.0 \%)$ \\
\hline \multicolumn{2}{|l|}{ Legal Jurisdiction } \\
\hline Settlement & $3(6.1 \%)$ \\
\hline Defendant Verdict & $30(61.2 \%)$ \\
\hline Plaintiff Verdict & $13(26.5 \%)$ \\
\hline Dismissed & $1(2.0 \%)$ \\
\hline $\mathrm{N} / \mathrm{A}$ & $2(4.1 \%)$ \\
\hline
\end{tabular}


*Some cases had more than 1 reason for litigation.

Table 3: Comparative analysis between Cases with Verdict in favor of Defendant and those in favor of Plaintiff. 


\begin{tabular}{|c|c|c|c|}
\hline & Defendant $(\mathrm{N}=30)$ & Plaintiff $(\mathrm{N}=13)$ & $\mathrm{p}$ value \\
\hline Type of Court & & & 0.521 \\
\hline Circuit Court & $4(13.3 \%)$ & $4(30.8 \%)$ & \\
\hline Court of Common Pleas & $6(20.0 \%)$ & $2(15.4 \%)$ & \\
\hline District Court & $3(10.0 \%)$ & $0(0.0 \%)$ & \\
\hline Superior Court & $9(30.0 \%)$ & $2(15.4 \%)$ & \\
\hline Supreme Court & $4(13.3 \%)$ & $3(23.1 \%)$ & \\
\hline Unknown State Court & $4(13.3 \%)$ & $2(15.4 \%)$ & \\
\hline State & & & 0.289 \\
\hline California & $4(13.3 \%)$ & $1(7.7 \%)$ & \\
\hline Colorado & $1(3.3 \%)$ & $0(0.0 \%)$ & \\
\hline Connecticut & $1(3.3 \%)$ & $0(0.0 \%)$ & \\
\hline Florida & $3(10.0 \%)$ & $1(7.7 \%)$ & \\
\hline Kansas & $1(3.3 \%)$ & $0(0.0 \%)$ & \\
\hline Kentucky & $0(0.0 \%)$ & $1(7.7 \%)$ & \\
\hline Maryland & $1(3.3 \%)$ & $0(0.0 \%)$ & \\
\hline Michigan & $1(3.3 \%)$ & $0(0.0 \%)$ & \\
\hline Minnesota & $1(3.3 \%)$ & $0(0.0 \%)$ & \\
\hline Missouri & $0(0.0 \%)$ & $3(23.1 \%)$ & \\
\hline New Jersey & $4(13.3 \%)$ & $1(7.7 \%)$ & \\
\hline New York & $6(20.0 \%)$ & $4(30.8 \%)$ & \\
\hline Ohio & $0(0.0 \%)$ & $1(7.7 \%)$ & \\
\hline Pennsylvania & $6(20.0 \%)$ & $1(7.7 \%)$ & \\
\hline Virginia & $1(3.3 \%)$ & $0(0.0 \%)$ & \\
\hline Location & & & 0.157 \\
\hline Academic & $1(6.2 \%)$ & $2(40.0 \%)$ & \\
\hline Private & $14(87.5 \%)$ & $3(60.0 \%)$ & \\
\hline Public & $1(6.2 \%)$ & $0(0.0 \%)$ & \\
\hline Patient Age & & & 0.030 \\
\hline
\end{tabular}




\begin{tabular}{|llll|}
\hline Mean (SD) & $42.9(12.5)$ & $55.6(12.9)$ & \\
\hline Range & $22.0-60.0$ & $29.0-67.0$ & \\
\hline Defendant Type & & & \\
\hline Hospital & $1(3.3 \%)$ & $0(0.0 \%)$ & \\
\hline Individual & $23(76.7 \%)$ & $7(53.8 \%)$ & 0.137 \\
\hline Multiple & $6(20.0 \%)$ & $6(46.2 \%)$ & \\
\hline Defendant's Position & & & \\
\hline Dentist & $21(70.0 \%)$ & $6(46.2 \%)$ & \\
\hline Physician & $9(30.0 \%)$ & $7(53.8 \%)$ & \\
\hline Malpractice vs Negligence & & & \\
\hline Malpractice & $11(36.7 \%)$ & $8(66.7 \%)$ & \\
\hline Negligence & $19(63.3 \%)$ & $4(33.3 \%)$ & \\
\hline Litigation Category & & $2(15.4 \%)$ & \\
\hline Failure to Diagnose & $11(36.7 \%)$ & $0(0.0 \%)$ & \\
\hline Failure to Provide Referral & $1(3.3 \%)$ & $3(23.1 \%)$ & \\
\hline Failure to Treat & $2(6.7 \%)$ & $5(38.5 \%)$ & \\
\hline Imaging or Surgical Complication & $15(50.0 \%)$ & $(3.3 \%)$ & \\
\hline Informed Consent Failure & $1(23.1 \%)$ & \\
\hline
\end{tabular}

\section{Figures}




\section{8}

16

14

12

ठे
$\frac{\bar{d}}{\mathrm{~g}}$
$\frac{\mathrm{d}}{4}$

10

8

6

4

0
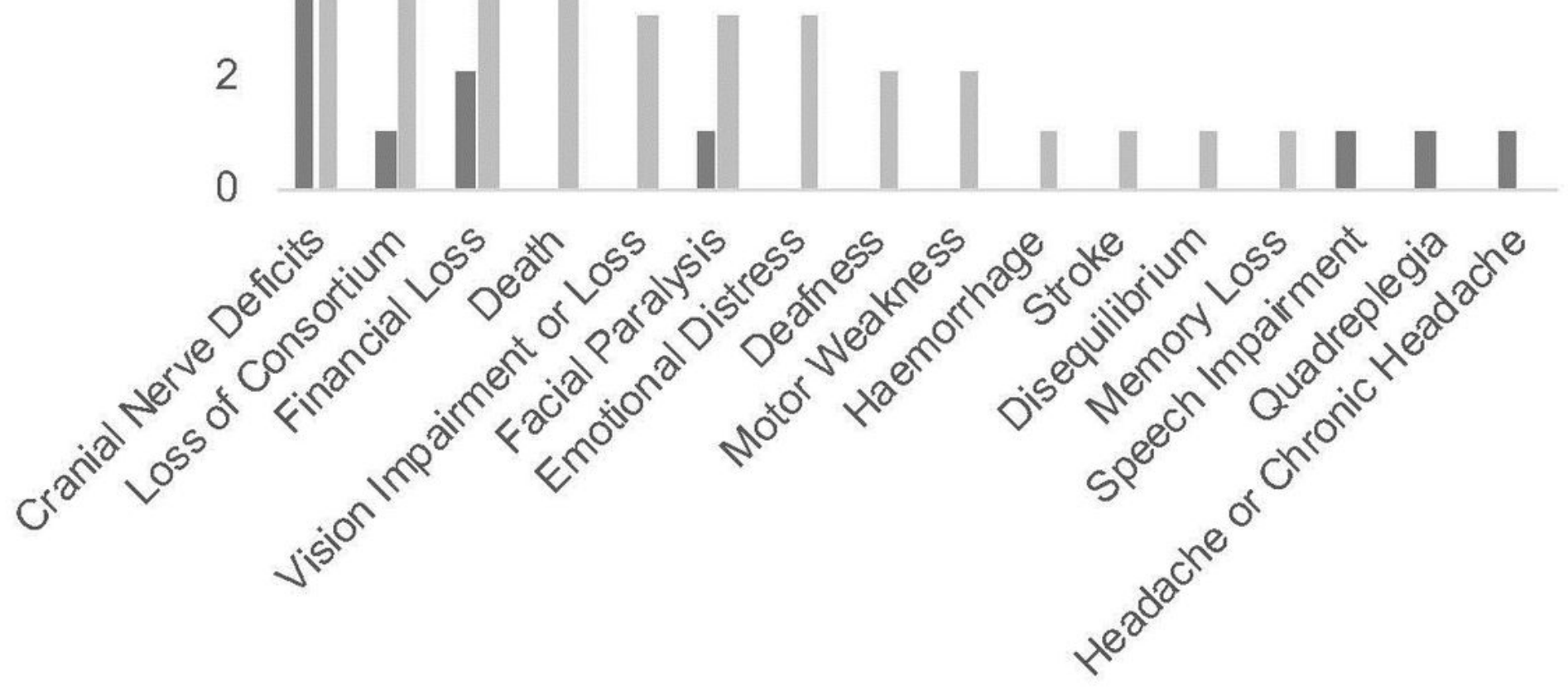

Plaintiff Complaint

\section{Figure 1}

The most frequent pre-operative plaintiff complaints were cranial nerve injury $(n=10 ; 20.4 \%)$ and financial loss $(n=2 ; 4.1 \%)$. The most frequent post-operative plaintiff complaints were cranial nerve injury $(n=17$; $34.7 \%)$, loss of consortium ( $n=6 ; 12.2 \%)$, and financial loss and death, both reported for $4(8.2 \%)$ cases. Additional post-operative symptoms included vision impairment or loss $(n=3 ; 6.1 \%)$ and facial paralysis $(n=3 ; 6.1 \%)$, followed by deafness $(n=2 ; 4.1 \%)$ and motor weakness $(n=2 ; 4.1 \%)$. 